\title{
Clinical role of bisphosphonate therapy
}

This article was published in the following Dove Press journal:

International Journal of Women's Health

3I August 2012

Number of times this article has been viewed

\author{
Geeta Hampson 1,2 \\ Ignac Fogelman ${ }^{1,3}$ \\ 'Osteoporosis Screening Unit, Guy's \\ Hospital, 'Department of Chemical \\ Pathology, St Thomas' Hospital, \\ ${ }^{3}$ Department of Nuclear Medicine, \\ Guy's Hospital, London, UK
}

\begin{abstract}
Bisphosphonates (BPs) are synthetic analogues of pyrophosphate. They inhibit bone resorption and are therefore widely used in disorders where there are increases or disruptions in bone resorption. This includes postmenopausal osteoporosis, glucocorticoid-induced osteoporosis, Paget's disease of bone, and malignancy-related bone loss. To best understand the clinical application of BPs, an understanding of their pharmacokinetics and pharmacodynamics is important. This review describes the structure, pharmacology and mode of action of BPs, focusing on their role in clinical practice. Controversies and side effects surrounding their use will also be discussed.
\end{abstract}

Keywords: pyrophosphate, bone resorption, postmenopausal osteoporosis, glucocorticoidinduced osteoporosis, Paget's disease of bone, malignancy-related bone loss

\section{Pharmacokinetics of bisphosphonates (BPs) Structure}

All BPs share a common P-C-P backbone. Unlike pyrophosphate, they have a carbon atom bridging the phosphate molecules and this renders them resistant to hydrolysis and degradation. In addition, BPs have two side-chains $\left(\mathrm{R}_{1}\right.$ and $\left.\mathrm{R}_{2}\right)$. Variations in the side-chains allow the synthesis of a number of analogues with varying pharmacological properties. $\mathrm{R}_{1}$ can either be hydrogen $(\mathrm{H})$, chloride $(\mathrm{CL})$, or hydroxyl $(\mathrm{OH})$, with the $\mathrm{OH}$ group imparting the highest affinity for calcium crystals, thus bone. The $\mathrm{R}_{2}$ sidechain can range from CL to more complex nitrogen $(\mathrm{N})$-containing organic structures. The presence of an $\mathrm{N}$ atom increases the potency of BPs. N-containing BPs - which include risedronate, ibandronate, pamidronate, alendronate, or zoledronate - can be 10-10,000-fold more potent than the non-N-containing BPs such as etidronate, clodronate, and tiludronate. ${ }^{1,2}$ Differences in affinity/potency also exist among the $\mathrm{N}$-containing BPs, as shown in Figure 1. However, the affinity data have been obtained from in vitro studies therefore may not necessarily be applicable in vivo. ${ }^{3}$ Caution also should be exercised when extrapolating these findings to compare the clinical efficacy of the various BPs.

\section{Pharmacology}

The clinical pharmacology of BPs is characterized by their poor oral bioavailability. Although there may be small differences among BPs, the most commonly used $\mathrm{N}$-containing BPs have an absorption $<1 \%$, due to the low efficiency of gastrointestinal (GI) uptake. ${ }^{2}$ This is decreased further by food intake, hence oral BPs should be taken in 


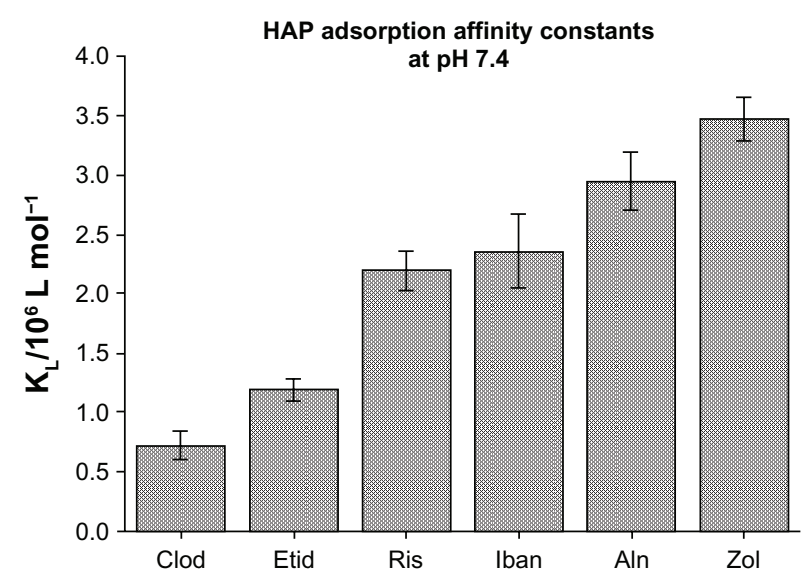

Figure I Hydroxyapatite (HAP) adsorption affinity constants vary between the different bisphosphonates. The hydroxyl position at RI as well as the R2 side-chain of BPs contribute to bone affinity.

(C)2006 Elsevier. Reproduced with permission from Nancollas GH, Tang R, Phipps $\mathrm{RJ}$ et al. Novel insights into actions of bisphosphonates on bone: differences in interactions with hydroxyapatite. Bone. 2006;38(5):617-627. ${ }^{86}$

Abbreviations: ALN, alendronate; CLO, clodronate; ETD, etidronate; IBN, ibandronate; RIS, risedronate; ZOL, zoledronate.

the fasting state. BPs can also be given intravenously, but this does not affect their bone accumulation or renal elimination.

The distribution of BPs is highly selective. Most circulating BPs $(\sim 50 \%)$ accumulate exclusively in bone, with extremely small amounts in soft tissues or organs such as the liver, kidneys, or spleen. The nonskeletal activity is cleared by renal excretion. ${ }^{3}$ The exact mechanism of skeletal uptake of BPs is still unclear but may involve a paracellular transport. Differences in skeletal uptake and retention have been documented and attributed to alterations in renal function and bone turnover rate, thus resulting in the delivery of different doses to the skeleton in the individual patient, despite the administration of the same treatment regime. ${ }^{3}$ Furthermore, the skeletal distribution of BPs is not even. Uptake is highest in the spine and lower in the femoral shaft. More recent studies show variation in the uptake of BPs in different types of bone, with higher uptake in trabecular bone than in cortical bone. There is also preferential uptake to active remodeling sites under osteoclasts or resorption surfaces, although absolute uptake seems more related to osteoblastic activity. ${ }^{3}$ However, distribution does not appear to be limited to the bone surface, as BPs can penetrate the osteocyte canalicular network. Penetration of the osteocytic network is better with BPs of weaker affinity. ${ }^{4}$

$\mathrm{N}$-containing BPs are excreted unmetabolized in the urine within 48 hours. Non-N-containing BPs are metabolized intracellularly, although how the metabolites are excreted remains unclear. Renal function is therefore an important consideration that applies to all BPs. ${ }^{3}$ In theory, dose adjustment can be made in renal impairment, although this is rarely carried out in practice. ${ }^{3}$ An important factor that can affect the rapidity of renal clearance, particularly when administered intravenously, is the extent of protein binding, which would affect the filtered load. Protein binding is higher for ibandronate than zoledronate. ${ }^{5}$ BPs bound to bone are slowly released back into the circulation during bone resorption and excreted in the urine over time, albeit in small amounts. After the initial rapid clearance, the slow elimination can take up to 12 years, which explains why bone turnover can still remain below baseline after discontinuation of BPs. ${ }^{6}$ This slow phase of the elimination, like skeletal retention, may be affected by the rate of bone turnover, although direct evidence is lacking. BPs can have very long-lasting effects on skeletal remodeling and this seems to be more prolonged with some BPs - for example zoledronate and alendronate compared with risedronate. These differences may be related to their binding affinity to hydroxyapatite.

\section{Mode of action}

As N-containing BPs localize to bone surfaces, they are taken up by osteoclasts. The BPs enter the osteoclasts through their ruffled borders, where the acidic environment liberates BPs from hydroxyapatite into solution. ${ }^{7}$ BPs enter the cells by liquid-phase endocytosis and exert their biological function upon release into the cytosol. The intracellular mechanisms of action on skeletal remodelling are complex. BPs can block osteoclastogenesis, promote osteoclast apoptosis, and inhibit osteoclast activity. ${ }^{8}$ BPs mainly exert their effects on mature osteoclasts. In organ cultures, some BPs have been shown to inhibit the formation of mature osteoclasts by inhibiting the fusion of osteoclast precursors into multinucleated osteoclasts, although this aspect of BP actions is understudied. BPs have been shown to induce osteoclast apoptosis by interfering with adenosine-5'-triphosphate-dependent cellular processes. This is the main mechanism of action of non-N-containing BPs. The main pathway by which $\mathrm{N}$-containing BPs inhibit bone resorption is by inhibition of osteoclast activity through disruption of the cytoskeleton, as shown in Figure 2. It has now become well established that, at the cellular level, N-containing BPs interfere with the mevalonate pathway. ${ }^{9}$ The major target is the enzyme farnesyl pyrophosphate synthase (FPPS). FPPS is required for the prenylation of small GTPases such as Ras, Rab, and Rho, which is essential for the function of these proteins. Small GTPases regulate a variety of cell processes that are important for osteoclast function, such as cell morphology, cytoskeletal arrangement, and membrane ruffling. The rank order of FPPS inhibition is: zoledronate $>$ risedronate $>$ ibandronate $>$ alendronate $>$ pamidronate. ${ }^{10}$ 


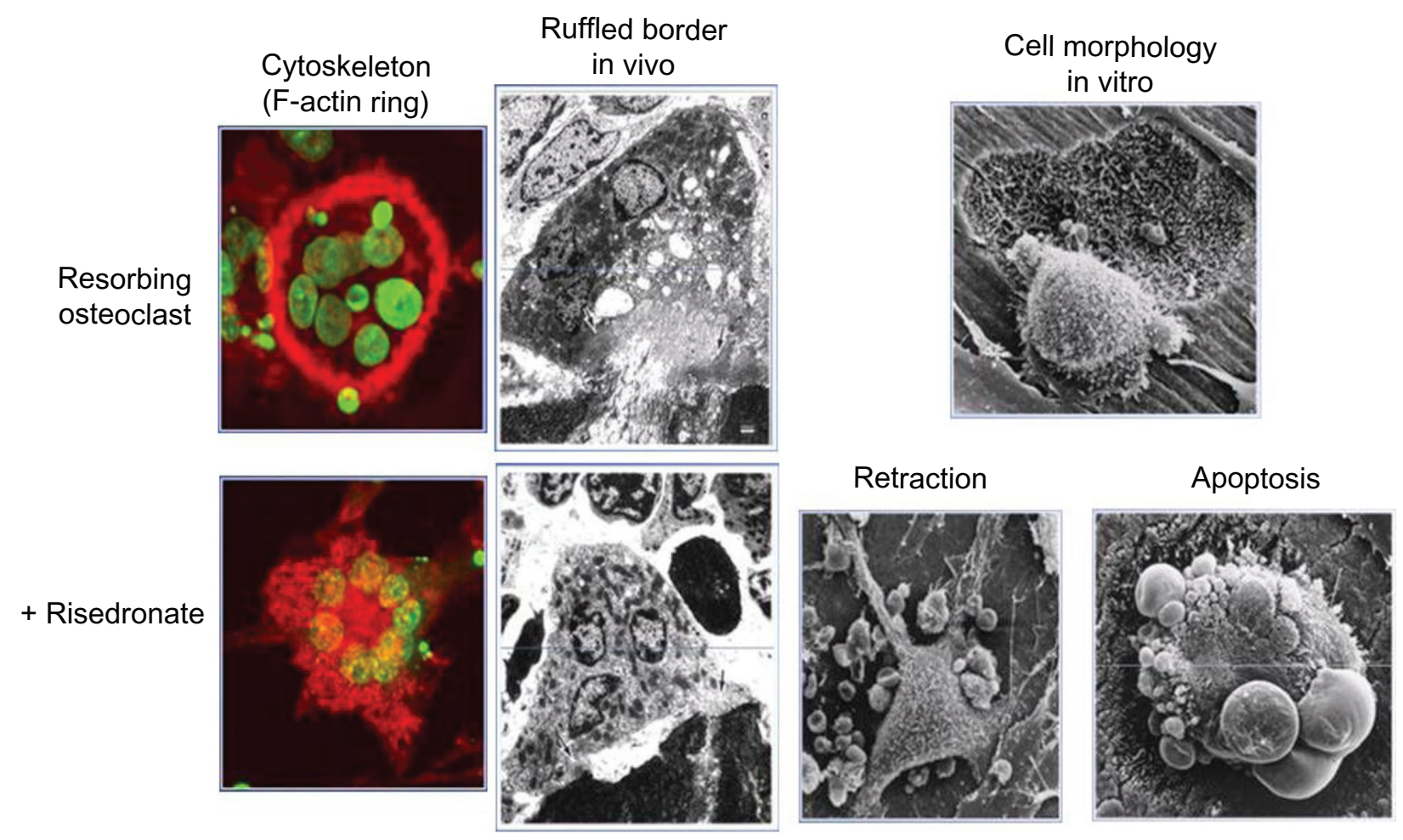

Figure 2 Effects of bisphosphonates on osteoclast morphology.

CI99I American Society for Clinical Investigation. Adapted with permission from Sato M, Grasser W, Endo N, et al. Bisphosphonate action. Alendronate localization in rat bone and effects on osteoclast ultrastructure. J Clin Invest. I99|;88(6):2095-2 105. ${ }^{87}$

Inhibition of bone resorption by BPs is dependent on the dose as well as the dosing interval with intermittent administration. ${ }^{3}$ However, as BPs reside in bone for a long time, daily, weekly, or even monthly administration should have similar efficacy, provided the cumulative doses are similar. This has been described for ibandronate and zoledronate when administration frequency is prolonged. ${ }^{11}$ During the period of treatment with BPs, bone resorption does not become progressively lower but reaches a new steady-state level, suggesting that, despite accumulation of BPs in the skeleton, bone turnover still continues, albeit at a slower rate.

In summary, the binding affinity of the various BPs as well as their FPPS inhibitory effect will affect their relative potency and bioactivity and probably explains some of the perceived differences in their clinical efficacy, which depend on their ability to inhibit osteoclastic activity together with their bone retention.

\section{Clinical uses of BPs BPs in postmenopausal osteoporosis (PMO)}

The common disease osteoporosis is a systemic skeletal disorder resulting in bone loss, disorganized bone micro-architecture, and increased fracture risk. It affects 1 in 3 women over the age of 50 years. With an increasing aging population, osteoporosis and its clinical sequelae are a major socioeconomic burden on health service resources. Treatment is aimed at reducing fracture risk. BPs are the most widely prescribed pharmacological treatment for PMO.

Several pivotal placebo-controlled trials and metaanalyses of these trials have shown the efficacy of BPs in decreasing bone resorption, improving bone mineral density (BMD), and reducing fracture risk. ${ }^{12-16}$ There is a reduction in bone resorption markers (urine N-terminal telopeptide, serum C-terminal telopeptide) following treatment with BPs by $>30 \%$ at 1 month, reaching a nadir by 3-6 months. Following the decline in bone resorption, bone formation rates also decrease and skeletal remodelling reaches a new lower steady state. In these trials, BPs also gave rise to modest improvements in BMD, although larger increases were seen at the spine compared with the hip. Gains in BMD ranging from $5 \%-7 \%$ have been observed at the lumbar spine. However, reductions in bone turnover and/or increases in BMD are surrogate outcomes. The most important clinical outcome of treatment is fracture reduction. Indeed, several trials of oral BPs (alendronate, risedronate, ibandronate), including the Fracture Intervention Trial (FIT-1 and FIT-2), 
Vertebral Efficacy with Risedronate Therapy-North America or MultiNational (VERT-NA and VERT-MN), and oral iBandronate Osteoporosis vertebral fracture trial in North America and Europe (BONE) have demonstrated significant reductions (of 40\%-50\%) in morphometric vertebral fractures after 3 years. ${ }^{12-15,17}$ This also applies to clinical vertebral fractures, although reductions were seen earlier as early as 6 months for risedronate. The effect of BPs on hip and nonvertebral fractures has been less consistent. Data support a $40 \%-50 \%$ reduction in hip fracture with some BPs including alendronate (FIT-1), risedronate (risedronate Hip Intervention Program) and more recently with zoledronate (HORIZON-PFT). ${ }^{13,16,18}$ The reduction in hip fracture seems more marked in the very-high-risk population with established osteoporosis. There are no published data on the effect of ibandronate on hip fracture. Data supporting reduction in nonvertebral fractures are also less clear, but reductions are modest, ranging from $20 \%$ to $39 \%$. Cochrane meta-analysis reported a risk reduction for nonvertebral fractures of $23 \%$ for alendronate and $20 \%$ for risedronate (VERT-NA and VERT-MN). ${ }^{13,17}$ As with vertebral fractures, the effect of BPs on risk reduction occurs early after treatment initiation. With ibandronate, a reduction in nonvertebral fractures of $69 \%$ was reported in a post-hoc analysis of a population at high risk. ${ }^{15}$ A $25 \%$ reduction in nonvertebral fractures and a $40 \%$ reduction in hip fractures has been reported with zoledronate (HORIZON-PFT, [HORIZON-PIVOTAL FRACTURE TRIAL], HORIZON-RFT [HORIZON-RECURRENT FRACTURE TRIAL]). ${ }^{16,19}$

All data from randomized controlled trials (RCTs) so far demonstrate that BPs are an effective treatment in PMO, as summarized in Table 1. However, there is some evidence to suggest that there are differences in efficacy among individual BPs, presumably due to variations in their skeletal retention time and potency. Comparisons among the pivotal RCTs of different BPs are difficult due to differences in trial design, study population entry criteria (such as severity of osteoporosis or prior fracture), and definitions used for the characterization of vertebral fractures. This limits the ability to directly compare the individual BPs in terms of their relative efficacy and time of onset of action.

Although there is a paucity of direct clinical trial comparisons, some head-to-head studies have been described. One study comparing the effects of alendronate and risedronate showed that alendronate was associated with greater gains in BMD and reductions in bone resorption, as shown in Figure $3 .^{20}$ Another study compared the effects of weekly alendronate with a single dose of zoledronate, showing that suppression of bone resorption was greater with zoledronate compared with alendronate. ${ }^{21}$ However, there were no data on fracture outcomes in either study. Some attempts have been made to generate comparative data through observational studies using information obtained from health care utilization records. In the RisedronatE and ALendronate (REAL) cohort study, patients receiving risedronate were found to have an $18 \%$ lower rate of hip fractures and $43 \%$ lower rate of nonvertebral fractures during their first year of treatment compared with patients receiving alendronate. ${ }^{22}$ In another observational study, the eValuation of IBandronate Efficacy (VIBE), the incidence of hip and nonvertebral fractures was similar in patients receiving monthly ibandronate, weekly alendronate, or weekly risedronate. ${ }^{23}$ However, the risk of vertebral fractures was lower in those receiving ibandronate. Calculating the number needed to treat (NNT) over a fixed period to prevent a fracture from the pivotal trials is another way of comparing efficacy. The NNT for hip fracture was similar for alendronate, risedronate, and zoledronate. However, caution should be exercised in the interpretation of data from observational studies or NNT due to the potential for introducing bias and variable compliance rates. NNT may also be dependent on the entry criteria for the individual RCTs, such as disease severity.

Duration of treatment with BPs for PMO remains a clinical issue and a subject of debate. Because of their long retention time in bone, in theory, their antifracture efficacy may persist long after treatment is discontinued. This has led to the concept of a "drug holiday," which is an attractive idea, particularly in light of potential serious side effects due to long-term suppression of skeletal remodelling. Information is available on the effect of discontinuation of alendronate, risedronate, and, more recently, zoledronate after long-term treatment. In the Fracture intervention trial Long-term EXtension (FLEX), those women who had previously been treated with alendronate for an average of 5 years continued for a further 5 years on either alendronate or placebo. ${ }^{6}$ The data show a small decline in BMD at the hip and spine in the placebo group. There was no difference in nonvertebral fractures between the two groups, although this must be interpreted with caution as the number of nonvertebral fractures was low and the study lacked power, particularly as many of the subjects did not have osteoporosis. However, the data showed a reduction in clinical vertebral fractures in the group who continued treatment with alendronate. Moreover, the risk of both nonvertebral and clinical fractures increased in patients with low BMD (T score $<-2.5$ ) or previous vertebral fractures, suggesting therefore that in those women at high 
Table I Randomized placebo-controlled trials of bisphosphonates in postmenopausal osteoporosis summarizing their effect on fracture risk

\begin{tabular}{|c|c|c|c|}
\hline \multirow[t]{2}{*}{ Bisphosphonate } & \multicolumn{3}{|c|}{ Average relative risk ( $95 \%$ confidence interval) } \\
\hline & Vertebral fracture & Nonvertebral fractures & Hip fracture \\
\hline \multicolumn{4}{|l|}{ Alendronate } \\
\hline FIT-I 12 & $0.53(0.4 \mathrm{I}-0.68)$ & $0.8(0.63-1.01)$ & $0.49(0.23-0.99)$ \\
\hline FIT- $2^{14}$ & $0.56(0.39-0.8)$ & $0.88(0.74-1.04)$ & $0.79(0.43-1.44)$ \\
\hline FLEX ${ }^{6}$ & $0.86(0.6-1.22)$ & $1.00(0.76-1.32)$ & $1.02(0.5 \mathrm{I}-2.10)$ \\
\hline \multicolumn{4}{|l|}{ Risedronate } \\
\hline VERT-NA'13 & $0.59(0.43-0.82)$ & $0.6(0.39-0.94)$ & Not available \\
\hline VERT-MN'17 & $0.5 \mathrm{I}(0.36-0.73)$ & $0.67(0.44-1.04)$ & Not available \\
\hline HIP'8 & Not available & $0.8(0.7-1.0)$ & $0.7(0.6-0.9)$ \\
\hline \multicolumn{4}{|l|}{ Ibandronate } \\
\hline BONE $E^{15}$ & $0.5(0.26-0.66)$ & Not available & Not available \\
\hline \multicolumn{4}{|l|}{ Intermittent dosing } \\
\hline \multicolumn{4}{|l|}{ Zoledronate } \\
\hline HORIZON-PFT'6 & $0.3(0.24-0.38)$ & $0.75(0.64-0.87)$ & $0.59(0.42-0.83)$ \\
\hline HORIZON-RFT' ${ }^{19}$ & $0.54(0.32-0.92)$ & $0.73(0.55-0.98)$ & $0.7(0.41-1.19)$ \\
\hline
\end{tabular}

Abbreviations: BONE, oral iBandronate Osteoporosis vertebral fracture trial in North America and Europe; FIT, Fracture Intervention Trial; FLEX, Fracture intervention trial Long-term EXtension; HIP, Hip Intervention Program; HORIZON-PFT; HORIZON-RFT; VERT-MN, Vertebral Efficacy with Risedronate Therapy-MultiNational; VERTNA, Vertebral Efficacy with Risedronate Therapy-North America.

fracture risk, treatment should be continued. The information concerning discontinuation of risedronate differs from that for alendronate. In the VERT-NA study, BMD decreased at 1 year off treatment, following 3 years treatment with risedronate. ${ }^{13}$ Bone turnover also increased and was similar to the placebo group after 12 months. However, the incidence of morphometric vertebral fractures was $46 \%$ lower than at baseline in the group previously on risedronate. These data indicate that the offset of treatment is shorter with risedronate than with alendronate. Recent reports from the 3-year extension of the pivotal HORIZON trial of annual infusions ( $5 \mathrm{mg}$ ) of zoledronate show a small decline in femoral neck BMD (1.04\%) in the placebo group compared with the group who continued zoledronate for a further 3 years, after the initial 3 years of study duration. ${ }^{24}$ There was no significant difference in nonvertebral, clinical vertebral, or all clinical fractures between the two groups, although the incidence of new morphometric vertebral fractures was higher in the group who switched to placebo after 3 years. These data suggest that zoledronate and alendronate have a longer effect on the skeleton after treatment is stopped than risedronate. A drug holiday may be considered after 5 years of treatment, particularly in those women who have responded well to BPs and who have not sustained any fractures during treatment. However, reassessment of fracture risk should be undertaken after 1 year for risedronate, after 1-2 years for alendronate, and after 2 years for zoledronate.

Another clinical issue concerning treatment with BPs is their use in postmenopausal women with osteopenia ( $\mathrm{T}$ scores between -1.0 and -2.5 ). This is an important consideration, as many fractures occur in women without a BMD diagnosis of osteoporosis. However, most clinical trials enrolled women with $\mathrm{T}$ scores $<-2.5$ or with previous fragility fractures, therefore information on the effect of BPs in osteopenia is limited. Post-hoc analyses of clinical trials of alendronate and risedronate have been inconclusive. ${ }^{14,25}$ Alendronate was shown to reduce the risk of vertebral fractures by $60 \%$ in women with osteopenia and previous vertebral fractures. ${ }^{14}$ The effect of alendronate was not significant in those who did not have a previous vertebral fracture. Treatment with risedronate for 3 years reduced the risk of fragility fractures in osteopenic women, with no significant effect on vertebral fractures in isolation, although this could be explained by the small number of subjects. ${ }^{25}$ The use of fracture prediction tools such as the World Health Organization Fracture Risk Assessment Tool $\left(\mathrm{FRAX}^{\circledR}\right)^{26}$ may be useful in this context as they may identify patients with osteopenia who have a high 10-year fracture risk and for whom treatment with BPs is likely to be of benefit. This warrants further clinical studies.

\section{BPs in glucocorticoid (GC)-induced osteoporosis}

GC-induced osteoporosis is the commonest cause of secondary osteoporosis. The prevalence of oral GC use is approximately $1 \%$ of the adult population and this increases to $2.5 \%$ in those aged $70-79$ years. ${ }^{27}$ GCs are commonly prescribed for patients with chronic inflammatory disorders such as rheumatoid arthritis, inflammatory bowel disease, and chronic obstructive pulmonary disease. GCs have a direct adverse effect on the skeleton. The cellular changes include decreased osteoblastogenesis and increased osteoblast 
A

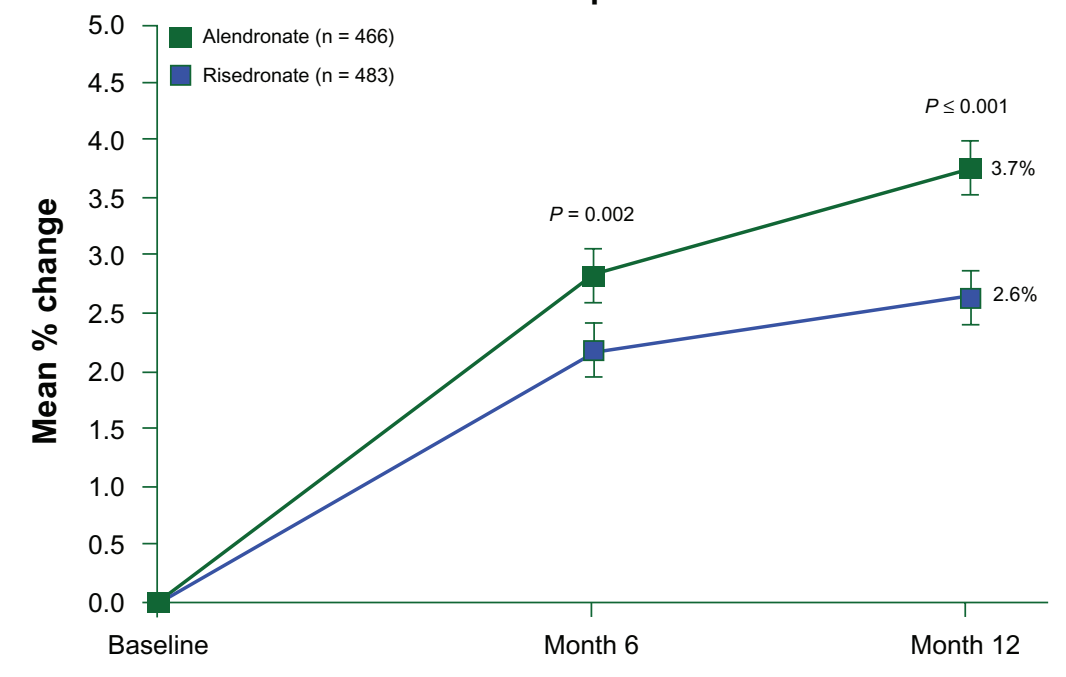

Treatment difference $=1.2 \%, P<0.001$

B

Bone resorption markers
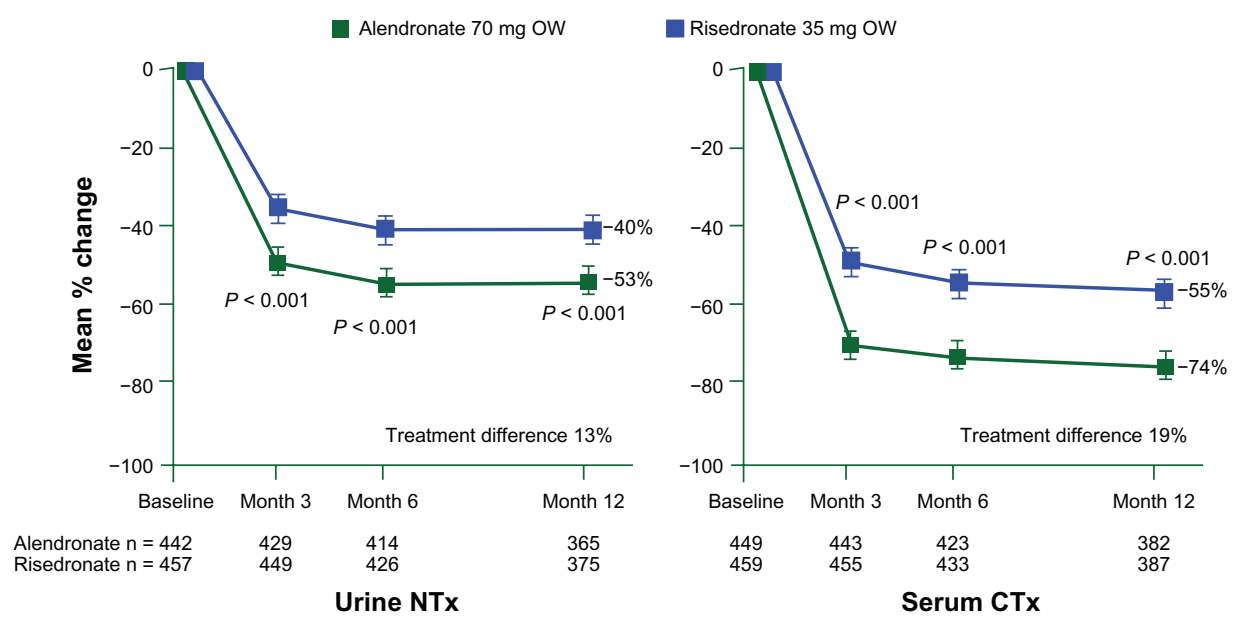

Figure 3 Changes in $(\mathbf{A})$ bone mineral density and $(\mathbf{B})$ markers of bone resorption expressed as percentage change from baseline during weekly (OW) alendronate (70 mg) and risedronate $(35 \mathrm{mg})$.

@2005 John Wiley and Sons. Reproduced with permission from Rosen CJ, Hochberg MC, Bonnick SL, et al; Fosamax Actonel Comparison Trial Investigators. Treatment with once-weekly alendronate $70 \mathrm{mg}$ compared with once-weekly risedronate $35 \mathrm{mg}$ in women with postmenopausal osteoporosis: a randomized double-blind study. J Bone Miner Res. 2005;20(I):141-151.20

Abbreviations: CTx, C-terminal telopeptide; NTx, N-terminal telopeptide.

apoptosis resulting in reduced bone formation..$^{28}$ Increased osteocyte apoptosis following exposure to GCs reduces bone quality. The effects of GC on bone resorption are more complex. An early rise in bone resorption occurs, which may be due to a transient increase in osteoclast survival. However, following long-term exposure to GCs, bone resorption diminishes due to decreased osteoclastogenesis. ${ }^{29}$ Indeed, prolonged treatment with GCs leads to a low bone turnover state with suppression of bone formation. In the early stages of GC use, bone loss is more pronounced as a result of the uncoupling of bone formation and resorption. Bone loss in
GIOP appears biphasic, with a larger reduction (3\%-5\%) in the first year followed by a slower decline (1\%-2\%) annually. ${ }^{30}$ The risk of fracture, particularly vertebral fracture, increases (two- to five-fold) as early as 3 months after GC treatment and depends on the daily dose. ${ }^{31}$ The increased fracture risk is apparent, particularly in patients on $>7.5 \mathrm{mg} /$ day of prednisolone (equivalent to $9.3 \mathrm{mg}$ of prednisone per day). The precise fracture risk on those on lower doses $(<5 \mathrm{mg}$ / day of prednisolone or $<6.2 \mathrm{mg} /$ day of prednisone) is still unclear, although treatment is recommended for older adults on lower GC doses who are deemed at high risk of fracture. ${ }^{32}$ 
This increased fracture risk occurs before any changes in BMD are seen, which suggests that some of the detrimental effects of GC on the skeleton and, in particular, changes in bone quality are not captured by bone densitometry. This therefore makes measurements of BMD insensitive in the identification of patients at high fracture risk. ${ }^{33}$ Nevertheless, several guidelines have used $\mathrm{T}$ scores to identify for therapy patients who have no previous fractures. These guidelines have taken into account the epidemiological observation that patients on GCs fracture at higher BMD. The American College of Rheumatology (ACR) 2001 guidelines recommend the use of a cut-off T score of $-1.0,{ }^{34}$ while the UK consensus group (Royal College of Physicians guidelines 2002) recommend treatment intervention at or below a $\mathrm{T}$ score of $-1.5 .^{33}$ The ACR 2010 guidelines suggest using FRAX risk assessment tool to determine treatment threshold. ${ }^{35}$ Those postmenopausal women or men over 50 with a 10 -year fracture probability of $<10 \%$ would be at low risk, those with probabilities between $10 \%$ and $20 \%$ would be considered as medium risk and those $>20 \%$ would be at high risk. However, this approach may be flawed in the context of GIOP, as the FRAX tool does not take into account the GC dose or duration of GC use and uses femoral neck BMD instead of lumbar spine. Other algorithms are available and can be used, such as the Fracture in GIOP Score. ${ }^{36}$

BPs are considered to be the first-line treatment for the prevention and treatment of GIOP. As GIOP is predominantly a disorder of bone formation, it is surprising that drugs such as BPs - which are primarily antiresorptive drugs - are useful. Recent evidence suggests that BPs can reduce GC-induced osteocyte apoptosis, which may have an impact on the preservation of bone strength. ${ }^{37}$ BPs may be also at their most effective during the first 2 years of GC treatment, when osteoclast activity is increased. Both alendronate and risedronate significantly improved BMD in patients on GC treatment. Alendronate reduced vertebral fractures after 2 years of treatment $(P=0.026) .{ }^{38}$ There was no significant reduction in nonvertebral fractures. Similar results were found in trials of risedronate (vertebral fractures; placebo: $16.2 \%$, risedronate: $5.4 \%, P=0.01) .{ }^{39}$ In a recent comparator trial of intravenous zoledronate and risedronate, zoledronate was found to be more effective at improving BMD after 12 months. However, the larger increases in BMD with zoledronate did not translate into a larger reduction in fracture rates. ${ }^{40}$ Ibandronate treatment for 12 months in men receiving GCs after cardiac transplantation showed a significant reduction in vertebral fractures (placebo: 53\%, ibandronate: 13\%). ${ }^{41}$ In theory, anabolic agents such as parathyroid hormone (1-34) analogues (teriparatide) should be superior to antiresorptive agents in the management of GIOP. In a recent trial comparing alendronate and teriparatide, those patients on teriparatide for 18 months showed a larger increase in BMD at the lumbar spine and higher reduction in new vertebral fractures rate. ${ }^{42}$ However, no significant difference was found in the nonvertebral fractures rate.

Although several RCTs have shown that BPs are effective in GIOP, the evidence in terms of fracture prevention, particularly nonvertebral fractures, is not as strong as in PMO. ${ }^{38,39}$ This is possibly due to the different pathogenesis of bone loss in GIOP compared with in PMO, which is primarily a disorder of increased bone resorption. Other explanations include variability in the study patients, who had a range of underlying diseases and were on varying GC doses for different lengths of time. Moreover, the trials were of relatively short duration (12-24 months) and were not powered to study any difference in hip fractures. As the RCTs were undertaken over no longer than 3 years, the efficacy and safety of long-term use of BPs in patients who require GC therapy for many years remains unknown. In clinical practice, as patients tend to lose bone when discontinuing BPs while remaining on GCs, BPs are usually prescribed as long as GC treatment is required. ${ }^{43}$ Drug holidays are not recommended in this clinical setting.

\section{BPs in Paget's disease of bone (PDB)}

PDB is a localized disorder of skeletal remodelling. It is the second most common bone disease after osteoporosis, affecting up to $3 \%$ of adults aged over 55 years. The prevalence increases with age. The UK has the highest incidence in the world, although PDB is also common in Western and southern Europe. ${ }^{44}$ The commonest sites of skeletal involvement are the pelvis $(70 \%)$, femur $(55 \%)$, lumbar spine $(53 \%)$, and skull $(42 \% \text {. })^{44} \mathrm{PDB}$ is caused by increased osteoclastic bone resorption with subsequent compensatory increases in new bone formation. Bone strength is weakened due to abnormal bone architecture as a result of abnormalities of the collagen fibers that are laid down in a disorganized mosaic pattern (woven bone) instead of the characteristic organized fashion (lamellar bone). The abnormalities lead to bone pain, increased deformity, and an increased risk of fracture. Focal osteolytic lesions are seen in the earlier phase of PDB and these develop progressively into sclerotic lesions. ${ }^{45}$ The aetiology is still unclear. Both the measles virus nucleocapsid and the sequestesome (SQSTM1) gene, which encodes the p62 protein, have been implicated in the pathogenesis of PDP, although their relative contributions remain to be established. It has been 
reported that osteoclasts from $70 \%$ of PDB patients express measles virus nucleocapsid. At least 21 genetic mutations in the SQSTM1/p62 protein gene have been linked to PDB, with the p62 ${ }^{\mathrm{P} 392 \mathrm{~L}}$ being the most frequent. ${ }^{45}$

Clinically, patients with PDB may be asymptomatic and PDB may be detected as an incidental finding during the course of other investigations. A significant proportion of patients with PDB (up to 50\%) have bone pain and experience complications such as osteoarthritis (joint pain secondary to PDB-related deformities), fractures, and nerve root compression. Symptoms and signs tend to occur in patients with polyostotic rather than monostotic involvement. Diagnosis is radiological: X-rays or bone scintigraphy, which is more sensitive in the assessment of skeletal involvement. ${ }^{46}$ Bone turnover markers provide an integrated index of disease activity. Serum total alkaline phosphatase is still the most commonly used test in clinical management, as it is widely available. Newer, more specific bone markers such as bone alkaline phosphatase, procollagen type 1 N-terminal propeptide, urinary $\mathrm{N}$-telopeptide of type 1 collagen (N-terminal telopeptide) or serum C-telopeptide of type 1 collagen (C-terminal telopeptide) have been shown to be superior in assessment of disease activity and response to therapy, particularly as serum total alkaline phosphatase may be within the reference range in monostotic PDB. ${ }^{45}$ The aim of treatment is to relieve bone pain, normalize bone turnover, heal existing skeletal lesions, and prevent recurrence and complications. BPs, particularly the N-containing BPs, are the treatment of choice for PDB. Several clinical trials of BPs have been described in PDB. ${ }^{47-50}$ These show that alendronate and risedronate are superior to etidronate, as evidenced by the proportion of patients with normal serum total alkaline phosphatase following treatment (etidronate: $15 \%$, alendronate: $63 \%$, risedronate: $73 \%$ ). ${ }^{47,48}$ There have been very few head-to-head trials, although in a small trial of previously untreated patients, oral alendronate (40 mg/day for 3 months) was found to be superior to intravenous pamidronate (60 mg every 3 months). ${ }^{50}$ Treatment with alendronate resulted in normalization of total alkaline phosphatase in $79 \%$ of patients compared with $14 \%$ in the pamidronate arm. One issue with the use of intravenous pamidronate is that consensus on a treatment regime has never been established. The most impressive data have been obtained with the use of zoledronate. ${ }^{51}$ A trial comparing a single infusion of $5 \mathrm{mg}$ of zoledronate with standard oral risedronate (30 mg daily for 2 months) demonstrated the superiority of zoledronate at suppressing alkaline phosphatase (in $88 \%$ of patients treated with zoledronate compared with $58 \%$ on risedronate).${ }^{51}$ Further follow-up showed continued suppression of bone turnover at 2 years in those patients treated with zoledronate. Indeed, a recent report confirmed that a single infusion of zoledronate sustained remission for up to 6.5 years and was accompanied by improved quality of life. ${ }^{52}$

When to treat patients with $\mathrm{PDB}$ remains a matter of debate. Bone pain is the only clinical symptom for which there is robust evidence concerning the usefulness of BPs, although, clinically, it may not always be possible to distinguish bone pain from osteoarthritic pain resulting from complications of PDB. Whether BPs prevent articular pain, hearing loss in patients with skull involvement, or skeletal deformities is still unclear. A recent prospective study, the Paget's Randomized trial of Intensive bisphosphonate treatment versus Symptomatic Management (PRISM) failed to show any beneficial effect of intensive BP therapy on fracture rates, quality of life, overall body pain, or bone pain. ${ }^{53}$ However, the trial was underpowered for the primary endpoint, which included clinical fractures at any site. In addition, treatment was given late in the disease process and the study duration was short. To carry out a more longterm trial would be not only costly but would also raise the ethical issue of leaving patients untreated for a long time, particularly as recent evidence (mentioned in the previous paragraph) indicates that a single infusion of zoledronate is effective in improving quality of life and normalizing bone turnover for 6.5 years (Figure 4). ${ }^{52}$ Therefore, because current therapy with potent BPs is associated with normalization of bone histology, healing of osteolytic lesions and deposition of normal lamellar bone, one can speculate that associated complications can be prevented if treatment is administered at an early stage. ${ }^{54}$ Until further evidence becomes available, those patients, particularly younger ones, who are asymptomatic but have evidence of metabolically active PDB at sites where potential for later complications exists should be offered treatment with BPs.

\section{BPs in oncology}

Metastatic bone disease (MBD) is common in patients with cancer and occurs in $70 \%$ of patients with advanced prostate and breast cancer. ${ }^{55}$ As many as $70 \%-95 \%$ of patients with multiple myeloma develop osteolytic lesions..$^{55}$ Bone metastases lead to destruction of skeletal integrity and enhanced bone resorption, resulting in bone pain, pathological fracture, spinal cord compression, and decreased survival. BPs have been used to treat not only hypercalcemia of malignancy 


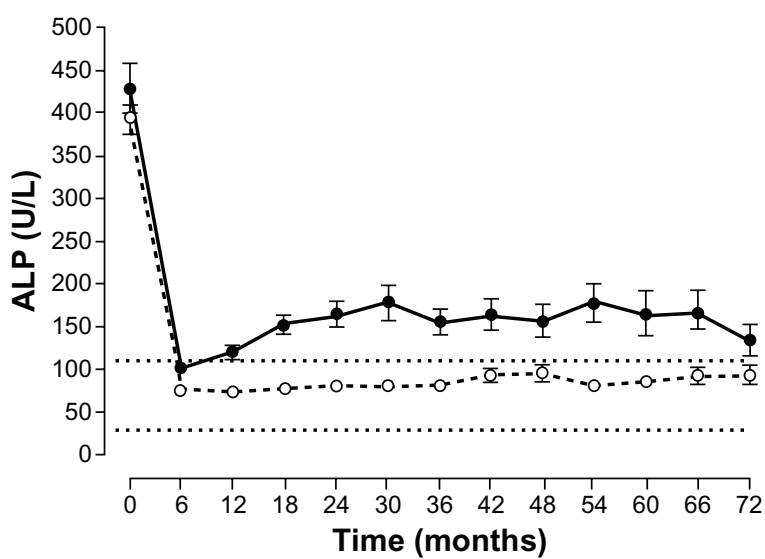

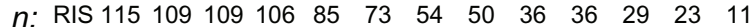

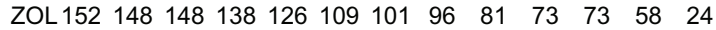

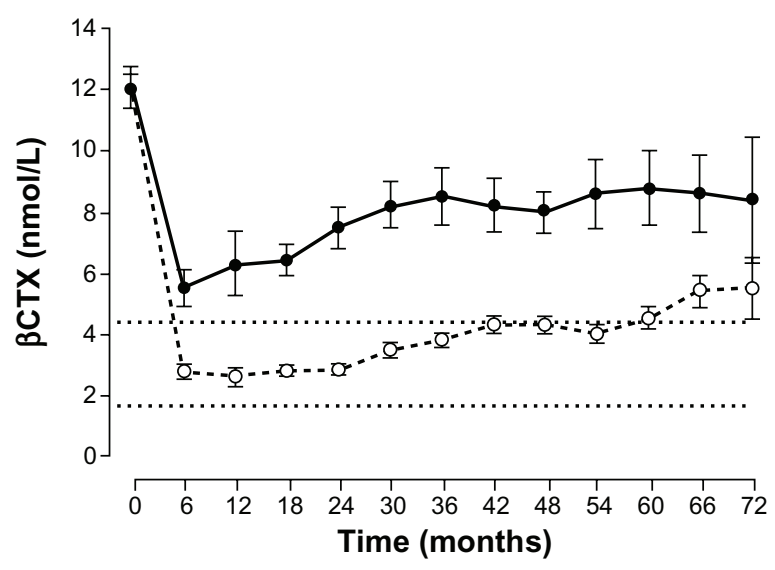

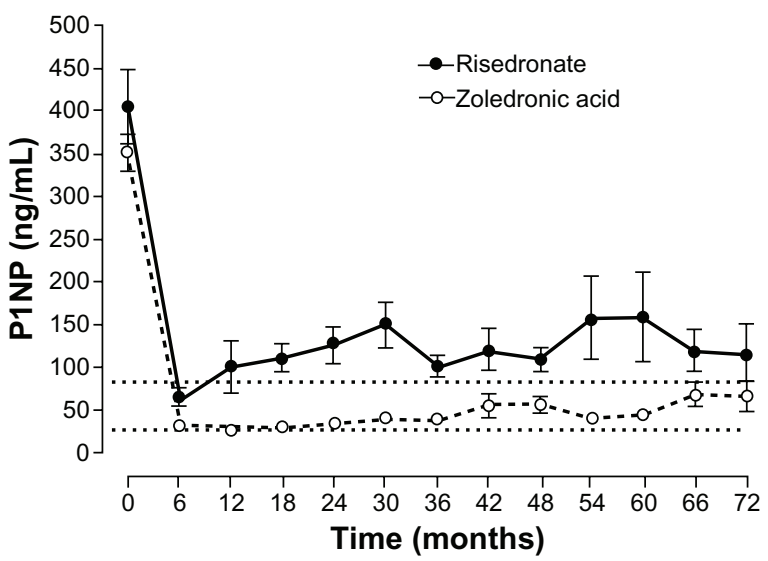

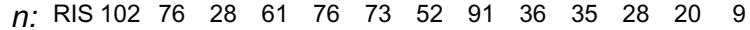

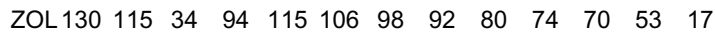

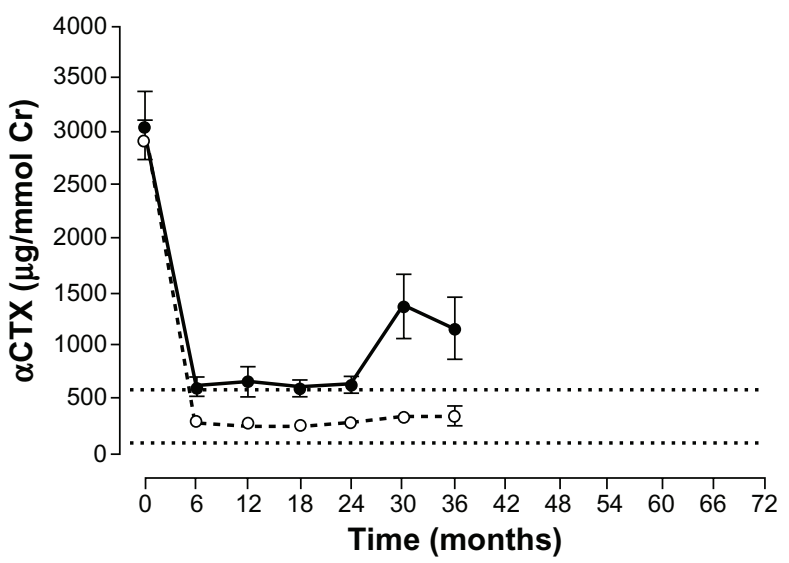

Figure 4 Changes in bone turnover markers following a single $5 \mathrm{mg}$ infusion of zoledronic acid (ZOL) or risedronate (RIS; $30 \mathrm{mg}$ orally for 60 days) for Paget's disease of bone. Notes: Bone turnover markers were lower in the zoledronic acid treatment arm throughout follow-up. Relapse rates were higher in the risedronate group (20\%) compared to the zoledronic acid group $(0.7 \%, P<0.00 \mathrm{I})$.

C20II John Wiley and Sons. Reproduced with permission from Reid IR, Lyles K, Su G, et al. A single infusion of zoledronic acid produces sustained remissions in Paget disease: data to 6.5 years. J Bone Miner Res. 201 I;26(9):226I-2270. ${ }^{52}$

Abbreviations: $\alpha C T X$, alpha C-terminal telopeptide; ALP, alkaline phosphatase; $\beta C T X$, beta C-terminal telopeptide; $\mathrm{Cr}$, creatinine; PINP, serum procollagen type I aminoterminal propeptide.

but also metastatic bone loss and to prevent skeletal cancerassociated skeletal complications.

Since the late 1990s, BP treatment has become the standard of care in patients with advanced breast cancer and MBD. Earlier studies with clodronate showed a $28 \%$ reduction in skeletal-related events (SREs). ${ }^{56}$ Further randomized trials with intravenous pamidronate demonstrated a reduction in SREs and increased time to progression (pamidronate: 13.1 months vs placebo: 7.0 months). ${ }^{57}$ Other clinical benefits of BP treatment included pain relief, improvement in performance status, and quality of life. Zoledronate infusion every 4 weeks in women with MBD from breast cancer reduced the risk of SREs by $41 \%{ }^{58}$ In a head-to-head study of zoledronate and pamidronate, zoledronate reduced the risk of skeletal complications by an additional $20 \%$ compared with pamidronate, although overall survival was not significantly different. ${ }^{59}$ The clinical value of intravenous ibandronate in this context is still unclear, although a trial of monthly infusions of $6 \mathrm{mg}$ significantly reduced the skeletal complications in breast cancer. ${ }^{60}$

In patients with hormone-resistant prostate cancer and MBD, a meta-analysis of ten RCTs showed a significant overall reduction in SRE rate (hazard ratio: $0.79, P=0.05) .{ }^{61}$ However, there was no change in overall or disease-free survival or in serum prostatic-specific antigen concentrations. Further studies with zoledronate showed a reduction in SREs of $36 \%$ in the treatment arm and prolonged time to occurrence of the first skeletal complication by more than 4 months. ${ }^{62}$ In multiple myeloma, BPs (oral clodronate and intravenous pamidronate and zoledronate) have been shown to reduce the risk of SREs, relieve bone pain, and increase survival. ${ }^{63}$ No significant differences were observed between the two agents in a recent randomized trial comparing zoledronate (4 mg) with pamidronate $(90 \mathrm{mg}$ ) single infusion every 3-4 weeks for 24 months. ${ }^{64}$ 
Although BPs are part of the standard of care in MBD, several questions remain about their use, including with regard to the timing and duration of treatment, particularly for the more potent agents. The current recommendation is to start BPs when MBD is diagnosed. However, the duration of treatment remains uncertain, as there is are no evidencebased criteria regarding their usefulness beyond 2 years. Consensus guidance recommends that all patients with breast cancer, hormone-resistant prostate cancer with MBD as well as patients with other solid tumors, such as renal carcinomas, be given BPs at the time of diagnosis. ${ }^{65}$ Using a potent BP such as zoledronate may be more desirable, provided that there are no contraindications such as creatinine clearance below $35 \mathrm{~mL} / \mathrm{min}$. In multiple myeloma, BP (intravenous zoledronate) is recommended in patients who do not have myeloma-related bone disease or lytic lesions at baseline but who are symptomatic. ${ }^{66}$ This is potentially of enormous clinical interest, as laboratory studies have shown that BPs may have a variety of antitumor effects ${ }^{67}$ Clinical benefits, including a reduction in the risk of death and improvement in progression-free survival, resulting from the early use of zoledronate rather than clodronate, have been shown in patients with multiple myeloma, irrespective of their bone disease status at baseline. ${ }^{68}$ However, questions remain as to whether BPs are useful in patients with solid tumors without bone metastases. Clinically, there have been mixed results on the ability of BPs to prevent the development of bone metastases in breast cancer patients in the adjuvant setting. Indeed, a recent study failed to demonstrate any benefits of routine intravenous zoledronate use in patients with early stage breast cancer without evidence of metastatic bone disease.$^{69}$ Further studies are required to test the antitumor effects of BPs in the clinical setting.

\section{Adverse effects of BPs}

As previously described, BPs have different potencies and are used at different doses, frequencies, via different routes of administration, and for several clinical indications. Taking into consideration the many facets of these compounds and their varied clinical uses, BPs are generally safe and well tolerated. The indications licensed for BP use are summarized in Table 2.

However, there have been some concerns in recent years surrounding their potential adverse effects. Some of these are well established while others remain the subject of controversy. For the oral BPs, GI side effects are the most frequently reported. This is due to local effects of BPs on the esophagus or gastric mucosa. The adverse events - which include dysphagia, esophagitis, and gastric ulcers - are the main cause of discontinuation of the drug in up to $20 \%$ of subjects. ${ }^{70}$ It is therefore important that patients are counseled at treatment start about the appropriate dosing protocol to avoid these side effects. The tablets must be taken with an adequate amount of water and patients should not lie down for some time after dosing. Recent concerns regarding the GI side effects relate to the use of generic formulations. ${ }^{71}$ Higher rates of GI intolerance have been observed following the introduction of generic alendronate (5.3/100 vs 1.2/100 patient years of exposure, $P<0.01)$. Differences in the formulation between generic and branded forms may be the cause. It has been suggested that rapid disintegration of the generic preparations may be the reason for poor tolerance and resulting lower adherence.

Intravenous BPs are used in patients unable to tolerate oral BPs due to adverse GI effects. Administration of intravenous BPs is associated with an acute-phase reaction in about $20 \%-30 \%$ of cases leading to transient flu-like symptoms. These symptoms usually occur after the first dose and last for a few days. ${ }^{72}$ Another important issue with the use of intravenous BPs is the potential for nephrotoxicity. For this reason, intravenous BPs should not be administered to patients with a glomerular filtration rate $<30 \mathrm{~mL} / \mathrm{min}(<35 \mathrm{~mL} / \mathrm{min}$ in the case of zoledronate). It is important to ensure that patients are well hydrated before intravenous BPs. They should be calcium and vitamin D replete, as sustained hypocalcemia can occur in severe vitamin D deficiency (serum $25(\mathrm{OH})$ vitamin $\mathrm{D}<25 \mathrm{nmol} / \mathrm{L}) .{ }^{69}$ Furthermore, it has been reported that more severe flu-like symptoms may occur in patients with poor vitamin D status. Serum 25-hydroxyvitamin D levels modulate the acute-phase response associated with the first nitrogen-containing bisphosphonate infusion. ${ }^{73}$

Recent concerns surrounding more serious adverse events - such as osteonecrosis of the jaw (ONJ), atypical femoral neck fractures, atrial fibrillation (AF), esophageal cancer, uveitis, and scleritis - remain controversial. ONJ - defined as delayed healing for more than 8 weeks, usually occurring after invasive dental procedures - has been reported to be associated with BP therapy. ${ }^{74}$ Although most cases have been observed in oncology patients on frequent administration of high-dose intravenous BPs, ONJ has also been reported in benign bone disease (PMO, Paget's disease, GIOP) following oral BPs. The current incidence ranges from 1 in 10,000 to 1 in 100,000 patient years for osteoporosis. The pathogenesis and scientific basis of ONJ is still unclear. Risk factors include trauma, radiotherapy to head and neck, chemotherapy, metastatic disease, surgical dental procedures, prior infection, alcohol or tobacco use, and BP therapy. Invasive dental and/ or oral procedures should be completed before initiating BP 


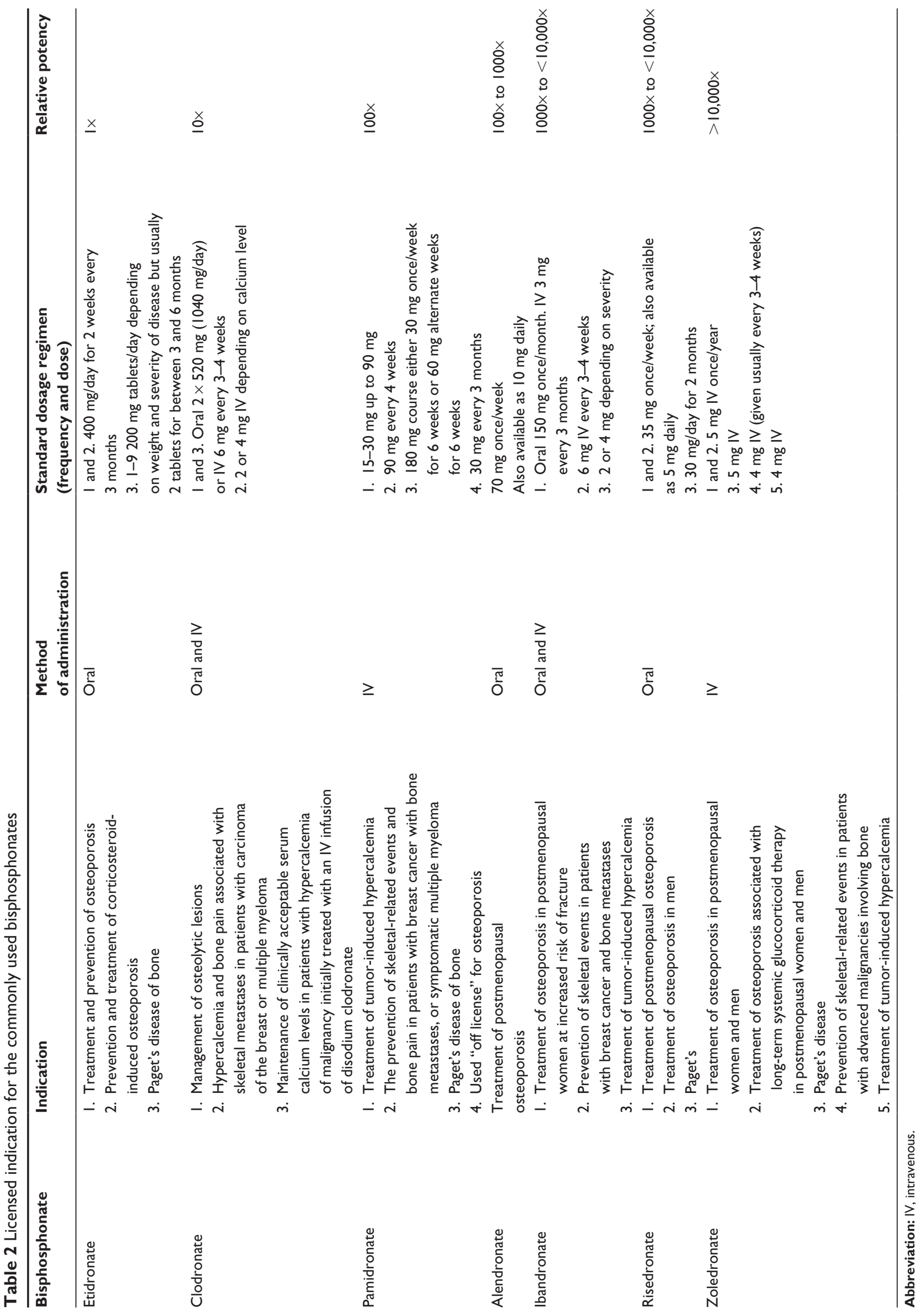


therapy. The risks associated with invasive dental treatment should be discussed with the patient and considered against the benefits of BP treatment.

The potential link between long-term BP use and atypical subtrochanteric fractures has become a subject of intense debate in recent years. ${ }^{75}$ Certain common radiological and clinical features have been reported. ${ }^{76}$ Most patients experienced prodromal thigh pain. The specific radiological findings include cortical hypertrophy within the femoral subtrochanteric region, often bilaterally. The emergence of this consistent clinical presentation has led to speculation about whether this constitutes a novel pattern, different to the existing description of subtrochanteric fractures. It has been suggested that prolonged suppression of skeletal remodelling and accumulation of micro-damage is the cause of these atypical fractures. However, post-hoc analyses of the FIT, FLEX, and HORIZON trials have failed to show a significant increase in subtrochanteric fractures in the treated arms. ${ }^{77}$ In contrast, epidemiological studies seem to support a link between BPs use (longer than 5 years) and an increased risk of these fractures, although the absolute fracture risk was low (absolute risk of 5 per 10,000 patient years compared with non-BP users) ${ }^{78}$ Subtrochanteric fractures are rare and constitute $<1 \%$ of all femoral fractures. However, because of the concerns and the ongoing debate, it is good clinical practice to restrict the use of BPs in high-risk patients and to reevaluate the indication for BPs in patients treated for longer than 5 years.

There have been reports of unexpected AF with BP use. In one study, AF occurred more frequently in patients treated with zoledronate than on placebo (50 patients compared with 20 on placebo, $P<0.01)$. ${ }^{16}$ Subsequent analyses, however, of other RCTs of zoledronate have not confirmed this finding. ${ }^{19}$ Secondary analyses of trials of alendronate (FIT-1 and FIT-2 study) reported a greater risk of $\mathrm{AF}^{79}$ Reassuringly, this has not been seen with other BPs. The clinical significance of this finding therefore remains unclear.

Likewise, the evidence about the association between BPs and esophageal cancer remains controversial. Two large cohort studies using the UK General Practice Research Database led to contradictory results. ${ }^{80,81}$ The first study found no difference in the risk of esophageal cancer between BPs users and nonusers. ${ }^{78}$ In the second study, the length of exposure to oral BPs was included in the analysis. ${ }^{79}$ The authors found an increase in the risk of esophageal cancer, particularly in those treated for longer than 3 years, compared with nonusers. Although those data are inconclusive, BPs should probably be avoided in patients with known esophageal abnormalities. Oral BPs are contraindicated in Barrett's esophagus.
Several case reports ${ }^{82,83}$ have highlighted the association between the use of oral BPs (alendronate and risedronate) and anterior uveitis and scleritis. In most of these case reports, severe eye pain occurred within days of taking oral BPs and resolved after discontinuation of the drugs. A large epidemiological study of a cohort of US veterans failed to find a significant association among BP users. ${ }^{84}$ However, a more recent retrospective study of a large cohort of residents of British Columbia showed an increased risk of uveitis (relative risk: 1.45) and scleritis (relative risk: 1.51) among first-time users of BPs, although the absolute number of cases was small (3.6\% among BP users compared with $1.8 \%$ in nonusers). ${ }^{85}$ The findings of this epidemiological study, although not definitive, suggest that it is important to inform patients of these potential side effects. If suspected, early assessment and intervention by an ophthalmologist is advised, as the conditions are potentially reversible.

\section{Conclusion}

It is generally agreed that the beneficial effects of BPs on fracture risk, in osteoporosis, $\mathrm{PDB}$, and in oncology patients with MBD greatly outweigh the known adverse effects. Despite various uncertainties that still exist regarding their long-term effects, the optimum length of treatment in a variety of clinical situations, and the differences in efficacy among the BPs, the risks associated with BPs are extremely small for most patients.

\section{Disclosure}

The authors declare no conflicts of interest in this work.

\section{References}

1. Russell RG. Bisphosphonates: the first 40 years. Bone. 2011;49(1):2-19.

2. Li B, Ling Chau JF, Wang X, Leong WF. Bisphosphonates, specific inhibitors of osteoclast function and a class of drugs for osteoporosis therapy. J Cell Biochem. 2011;112:1229-1242.

3. Cremers S, Papapoulos S. Pharmacology of bisphosphonates. Bone. 2011;49(1):42-49.

4. Roelofs AJ, Coxon FP, Ebetino FH, et al. Fluorescent risedronate analogues reveal bisphosphonate uptake by bone marrow monocytes and localization around osteocytes in vivo. J Bone Miner Res. 2010;25(3):606-616.

5. Lewiecki EM, Miller PD. Renal safety of intravenous bisphosphonates in the treatment of osteoporosis. Expert Opin Drug Saf. 2007;6(6):663-672.

6. Black DM, Schwartz AV, Ensrud KE, et al. Effects of continuing or stopping alendronate after 5 years of treatment: the Fracture Intervention Trial Long-term Extension (FLEX): a randomized trial. JAMA. 2006;296(24):2927-2938.

7. Coxon FP, Thompson K, Roelofs AJ, Ebetino FH, Rogers MJ. Visualizing mineral binding and uptake of bisphosphonate by osteoclasts and nonresorbing cells. Bone. 2008;42(5):848-860.

8. Rodan GA, Reszka AA. Bisphosphonate mechanism of action. Current Mol Med. 2002;2:571-577. 
9. Amin D, Cornell SA, Gustafson SK, et al. Bisphosphonates used for the treatment of bone disorders inhibit squalene synthase and cholesterol biosynthesis. J Lipid Res. 1992;33(11):1657-1663.

10. Russell RG, Watts NB, Ebetino FH, Rogers MJ. Mechanisms of action of bisphosphonates: similarities and differences and their potential influence on clinical efficacy. Osteoporos Int. 2008;19(6):733-759.

11. Papapoulos SE, Schimmer RC. Changes in bone remodelling and antifracture efficacy of intermittent bisphosphonate therapy: implications from clinical studies with ibandronate. Ann Rheum Dis. 2007;66(7):853-858.

12. Black DM, Cummings SR, Karpf DB, et al. Randomised trial of effect of alendronate on risk of fracture in women with existing vertebral fractures. Fracture Intervention Trial Research Group. Lancet. 1996;348(9041):1535-1541.

13. Harris ST, Watts NB, Genant HK, et al. Effects of risedronate treatment on vertebral and nonvertebral fractures in women with postmenopausal osteoporosis: a randomized controlled trial. Vertebral Efficacy With Risedronate Therapy (VERT) Study Group. JAMA 1999;282(14):1344-1352.

14. Cummings SR, Black DM, Thompson DE, et al; Fracture Intervention Trial Research Group. Effect of alendronate on risk of fracture in women with low bone density but without vertebral fractures: results from the Fracture Intervention Trial. JAMA. 1998;280(24):2077-2082.

15. Chesnut IC III, Skag A, Christiansen C, et al; Oral Ibandronate Osteoporosis Vertebral Fracture Trial in North America and Europe (BONE). Effects of oral ibandronate administered daily or intermittently on fracture risk in postmenopausal osteoporosis. J Bone Miner Res. 2004;19(8):1241-1249.

16. Black DM, Delmas PD, Eastell R, et al; HORIZON Pivotal Fracture Trial. Once-yearly zoledronic acid for treatment of postmenopausal osteoporosis. N Engl J Med. 2007;356(18):1809-1822.

17. Reginster J, Minne HW, Sorensen OH, et al. Randomized trial of the effects of risedronate on vertebral fractures in women with established postmenopausal osteoporosis. Vertebral Efficacy with Risedronate Therapy (VERT) Study Group. Osteoporos Int. 2000;11(1): 83-91.

18. McClung MR, Geusens P, Miller PD, et al; Hip Intervention Program Study Group. Effect of risedronate on the risk of hip fracture in elderly women. Hip Intervention Program Study Group. $N$ Engl J Med. 2001;344(5):333-340.

19. Lyles KW, Colon-Emeric CS, Magaziner JS, et al. Zoledronic acid and clinical fractures and mortality after hip fracture. $N$ Engl J Med. 2007;357(18):1799-1809.

20. Rosen CJ, Hochberg MC, Bonnick SL, et al; Fosamax Actonel Comparison Trial Investigators. Treatment with once-weekly alendronate $70 \mathrm{mg}$ compared with once-weekly risedronate $35 \mathrm{mg}$ in women with postmenopausal osteoporosis: a randomized double-blind study. J Bone Miner Res. 2005;20(1):141-151.

21. Saag K, Lindsay R, Kriegman A, Beamer E, Zhou W. A single zoledronic acid infusion reduces bone resorption markers more rapidly than weekly oral alendronate in postmenopausal women with low bone mineral density. Bone. 2007;40(5):1238-1243.

22. Silverman SL, Watts NB, Delmas PD, Lange JL, Lindsay R. Effectiveness of bisphosphonates on nonvertebral and hip fractures in the first year of therapy: the risedronate and alendronate (REAL) cohort study. Osteoporos Int. 2007;18(1):25-34.

23. Harris ST, Reginster JY, Harley C, et al. Risk of fracture in women treated with monthly oral ibandronate or weekly bisphosphonates: the eValuation of IBandronate Efficacy (VIBE) database fracture study. Bone. 2009;44(5):758-765.

24. Black DM, Reid IR, Boonen S, et al. The effect of 3 versus 6 years of zoledronic acid treatment of osteoporosis: a randomized extension to the HORIZON-Pivotal Fracture Trial (PFT). J Bone Miner Res. 2012;27(2):243-254

25. Siris ES, Simon JA, Barton IP, McClung MR, Grauer A. Effects of risedronate on fracture risk in postmenopausal women with osteopenia. Osteoporos Int. 2008;19(5):681-686.
26. Kanis JA, Oden A, Johnell O, et al. The use of clinical risk factors enhances the performance of BMD in the prediction of hip and osteoporotic fractures in men and women. Osteoporos Int. 2007;18:1033-1046.

27. van Staa TP, Leufkens HG, Cooper C. The epidemiology of corticosteroid-induced osteoporosis: a meta-analysis. Osteoporos Int. 2002;13(10):777-787.

28. Weinstein RS, Jilka RL, Parfitt AM, Manolagas SC. Inhibition of osteoblastogenesis and promotion of apoptosis of osteoblasts and osteocytes by glucocorticoids. Potential mechanisms of their deleterious effects on bone. J Clin Invest. 1998;102(2):274-282.

29. Teitelbaum SL, Seton MP, Saag KG. Should bisphosphonates be used for long-term treatment of glucocorticoid-induced osteoporosis? Arthritis Rheum. 2011;63(2):325-328.

30. LoCascio V, Bonucci E, Imbimbo B, et al. Bone loss in response to long-term glucocorticoid therapy. Bone Miner. 1990;8(1):39-51.

31. van Staa TP. The pathogenesis, epidemiology and management of glucocorticoid-induced osteoporosis. Calcif Tissue Int. 2006;79(3):129-137.

32. Hansen KE, Wilson HA, Zapalowski C, Fink HA, Minisola S, Adler RA. Uncertainties in the prevention and treatment of glucocorticoidinduced osteoporosis. J Bone Miner Res. 2011;26(9):1989-1996.

33. Van Staa TP, Laan RF, Barton IP, Cohen S, Reid DM, Cooper C. Bone density threshold and other predictors of vertebral fracture in patients receiving oral glucocorticoid therapy. Arthritis Rheum. 2003;48(11):3224-3229.

34. American College of Rheumatology Ad Hoc Committee on Glucocorticoid-induced Osteoporosis: Recommendations for the prevention and treatment of glucocorticoid-induced osteoporosis. Arthritis Rheum. 2001,44:1496-1503.

35. Grossman JM, Gordon R, Ranganath VK, et al. American College of Rheumatology 2010 recommendations for the prevention and treatment of glucocorticoid-induced osteoporosis. Arthritis Care Res (Hoboken). 2010;62(11):1515-1526.

35. den Uyl D, Bultink IE, Lems WF. Advances in glucocorticoid-induced osteoporosis. Curr Rheumatol Rep. 2011;13(3):233-240.

37. Plotkin LI, Weinstein RS, Parfitt AM, Roberson PK, Manolagas SC, Bellido T. Prevention of osteocyte and osteoblast apoptosis by bisphosphonates and calcitonin. J Clin Invest. 1999;104(10):1363-1374.

38. Adachi JD, Saag KG, Delmas PD, et al. Two-year effects of alendronate on bone mineral density and vertebral fracture in patients receiving glucocorticoids: a randomized, double-blind, placebo-controlled extension trial. Arthritis Rheum. 2001;44(1):202-211.

39. Wallach S, Cohen S, Reid DM, et al. Effects of risedronate treatment on bone density and vertebral fracture in patients on corticosteroid therapy. Calcif Tissue Int. 2000;67(4):277-285.

40. Reid DM, Devogelaer JP, Saag K, et al; HORIZON investigators. Zoledronic acid and risedronate in the prevention and treatment of glucocorticoid-induced osteoporosis (HORIZON): a multicentre, double-blind, double-dummy, randomised controlled trial. Lancet. 2009;373(9671):1253-1263.

41. Fahrleitner-Pammer A, Piswanger-Soelkner JC, Pieber TR, et al. Ibandronate prevents bone loss and reduces vertebral fracture risk in male cardiac transplant patients: a randomized double-blind, placebocontrolled trial. J Bone Miner Res. 2009;24(7):1335-1344.

42. Saag KG, Shane E, Boonen S, et al. Teriparatide or alendronate in glucocorticoid-induced osteoporosis. $N$ Engl J Med. 2007;357(20): 2028-2039.

43. Weinstein RS. Clinical practice. Glucocorticoid-induced bone disease. N Engl J Med. 2011;365(1):62-70.

44. Ralston SH, Albagha OM. Genetic determinants of Paget's disease of bone. Ann N Y Acad Sci. 2011;1240:53-60.

45. Michou L, Brown JP. Emerging strategies and therapies for treatment of Paget's disease of bone. Drug Des Devel Ther. 2011;5:225-239.

46. Singer FR. Paget disease: when to treat and when not to treat. Nat Rev Rheumatol. 2009;5(9):483-489.

47. Siris E, Weinstein RS, Altman R, et al. Comparative study of alendronate versus etidronate for the treatment of Paget's disease of bone. J Clin Endocrinol Metab. 1996;81(3):961-967. 
48. Miller PD, Brown JP, Siris ES, Hoseyni MS, Axelrod DW, Bekker PJ. A randomized, double-blind comparison of risedronate and etidronate in the treatment of Paget's disease of bone. Paget's Risedronate/Etidronate Study Group. Am J Med. 1999;106(5):513-520.

49. Stone MD, Hawthorne AB, Kerr D, Webster G, Hosking DJ. Treatment of Paget's disease with intermittent low-dose infusions of disodium pamidronate (APD). J Bone Miner Res. 1990;5(12):1231-1235.

50. Walsh JP, Ward LC, Stewart GO, et al. A randomized clinical trial comparing oral alendronate and intravenous pamidronate for the treatment of Paget's disease of bone. Bone. 2004;34(4):747-754.

51. Reid IR, Miller P, Lyles K, et al. Comparison of a single infusion of zoledronic acid with risedronate for Paget's disease. NEngl J Med. 2005; 353(9):898-908.

52. Reid IR, Lyles K, Su G, et al. A single infusion of zoledronic acid produces sustained remissions in Paget disease: data to 6.5 years. J Bone Miner Res. 2011;26(9):2261-2270.

53. Langston AL, Campbell MK, Fraser WD, MacLennan GS, Selby PL, Ralston SH; PRISM Trial Group. Randomized trial of intensive bisphosphonate treatment versus symptomatic management in Paget's disease of bone. J Bone Miner Res. 2010;25(1):20-31.

54. Reid IR, Nicholson GC, Weinstein RS, et al. Biochemical and radiologic improvement in Paget's disease of bone treated with alendronate: a randomized, placebo-controlled trial. Am J Med. 1996; 101(4):341-348

55. Coleman RE. Clinical features of metastatic bone disease and risk of skeletal morbidity. Clin Cancer Res. 2006;12:6243s-6249s.

56. Paterson AH, Powles TJ, Kanis JA, McCloskey E, Hanson J, Ashley S. Double-blind controlled trial of oral clodronate in patients with bone metastases from breast cancer. J Clin Oncol. 1993;11(1):59-65.

57. Hultborn R, Gundersen S, Rydén S, et al. Efficacy of pamidronate in breast cancer with bone metastases: a randomized double-blind placebo controlled multicenter study. Acta Oncol. 1996;35 Suppl 5:73-74.

58. Kohno N, Aogi K, Minami H, et al. Zoledronic acid significantly reduces skeletal complications compared with placebo in Japanese women with bone metastases from breast cancer: a randomized, placebo-controlled trial. J Clin Oncol. 2005;23(15):3314-3321.

59. Rosen LS, Gordon D, Kaminski M, et al. Zoledronic acid versus pamidronate in the treatment of skeletal metastases in patients with breast cancer or osteolytic lesions of multiple myeloma: a phase III, double-blind, comparative trial. Cancer J. 2001;7(5):377-387.

60. Body JJ, Diel IJ, Lichinitzer M, et al. Oral ibandronate reduces the risk of skeletal complications in breast cancer patients with metastatic bone disease: results from two randomised, placebo-controlled phase III studies. Br J Cancer. 2004;90(6):1133-1137.

61. Berry S, Waldron T, Winquist E, Lukka $\mathrm{H}$. The use of bisphosphonates in men with hormone-refractory prostate cancer: a systematic review of randomized trials. Can J Urol. 2006;13(4):3180-3188.

62. Saad F, Gleason DM, Murray R, et al; Zoledronic Acid Prostate Cancer Study Group. A randomized, placebo-controlled trial of zoledronic acid in patients with hormone-refractory metastatic prostate carcinoma. J Natl Cancer Inst. 2002;94(19):1458-1468.

63. Terpos E, Dimopoulos MA, Berenson J. Established role of bisphosphonate therapy for prevention of skeletal complications from myeloma bone disease. Crit Rev Oncol Hematol. 2011;77 Suppl $1: \mathrm{S} 13-\mathrm{S} 23$.

64. Rosen LS, Gordon D, Kaminski M, et al. Long-term efficacy and safety of zoledronic acid compared with pamidronate disodium in the treatment of skeletal complications in patients with advanced multiple myeloma or breast carcinoma: a randomized, double-blind, multicenter, comparative trial. Cancer. 2003;98(8):1735-1744.

65. Aapro M, Abrahamsson PA, Body JJ, et al. Guidance on the use of bisphosphonates in solid tumours: recommendations of an international expert panel. Ann Oncol. 2008;19(1):420-432.

66. Bird JM, Owen RG, D'Sa S, et al; Haemato-oncology Task Force of British Committee for Standards in Haematology (BCSH) and UK Myeloma Forum. Guidelines for the diagnosis and management of multiple myeloma 2011. Br J Haematol. 2011;154(1):32-75.
67. Berenson JR. Antitumor effects of bisphosphonates: from the laboratory to the clinic. Curr Opi Support Palliat Care. 2011;5(3):233-240.

68. Morgan GJ, Child JA, Gregory WM, et al; National Cancer Research Institute Haematological Oncology Clinical Studies Group. Effects of zoledronic acid versus clodronic acid on skeletal morbidity in patients with newly diagnosed multiple myeloma (MRC Myeloma IX): secondary outcomes from a randomised controlled trial. Lancet Oncol. 2011;12(8):743-752.

69. Coleman RE, Marshall H, Cameron D, et al; AZURE Investigators. Breast-cancer adjuvant therapy with zoledronic acid. $N$ Engl $J$ Med. 2011;365(15):1396-1405.

70. Reid IR. Bisphosphonates in the treatment of osteoporosis: a review of their contribution and controversies. Skeletal Radiol. 2011;40(9):1191-1196.

71. Kanis JA, Reginster JY, Kaufman JM, et al. A reappraisal of generic bisphosphonates in osteoporosis. Osteoporos Int. 2012;23(1): 213-221.

72. Reid IR, Gamble GD, Mesenbrink P, Lakatos P, Black DM. Characterization of and risk factors for the acute-phase response after zoledronic acid. J Clin Endocrinol Metab. 2010;95(9):4380-4387.

73. Bertoldo F, Pancheri S, Zenari S, et al. Serum 25-hydroxyvitamin D levels modulate the acute-phase response associated with the first nitrogen-containing bisphosphonate infusion. J Bone Miner Res. 2010 Mar; 25(3):447-454

74. Khosla S, Burr D, Cauley J, et al; American Society for Bone and Mineral Research. Bisphosphonate-associated osteonecrosis of the jaw: report of a task force of the American Society for Bone and Mineral Research. J Bone Miner Res. 2007;22(10):1479-1491.

75. Yoon RS, Hwang JS, Beebe KS. Long-term bisphosphonate usage and subtrochanteric insufficiency fractures: a cause for concern? J Bone Joint Surg Br. 2011;93(10):1289-1295.

76. Pathophysiology of atypical femoral fractures and osteonecrosis of the jaw. Compston J Osteoporos Int. 2011 Dec;22(12):2951-2961.

77. Black DM, Kelly MP, Genant HK, et al; Fracture Intervention Trial Steering Committee; HORIZON Pivotal Fracture Trial Steering Committee. Bisphosphonates and fractures of the subtrochanteric or diaphyseal femur. N Engl J Med. 2010;362(19):1761-1771.

78. Park-Wyllie LY, Mamdani MM, Juurlink DN, et al. Bisphosphonate use and the risk of subtrochanteric or femoral shaft fractures in older women. JAMA. 2011;305(8):783-789.

79. Cummings SR, Schwartz AV, Black DM. Alendronate and atrial fibrillation. N Engl J Med. 2007;356(18):1895-1896.

80. Cardwell CR, Abnet CC, Cantwell MM, Murray LJ. Exposure to oral bisphosphonates and risk of esophageal cancer. JAMA. 2010;304(6):657-663.

81. Green J, Czanner G, Reeves G, Watson J, Wise L, Beral V. Oral bisphosphonates and risk of cancer of oesophagus, stomach, and colorectum: case-control analysis within a UK primary care cohort. $B M J$. 2010;341:c4444.

82. Kilickap S, Ozdamar Y, Altundag MK, Dizdar O. A case report: zoledronic acid-induced anterior uveitis. Med Oncol. 2008;25(2): 238-240.

83. Peterson JD, Bedrossian EH Jr. Bisphosphonate-associated orbital inflammation - a case report and review. Orbit. 2012 Apr;31(2): 119-123.

84. French DD, Margo CE. Postmarketing surveillance rates of uveitis and scleritis with bisphosphonates among a national veteran cohort. Retina. 2008;28(6):889-893.

85. Etminan M, Forooghian F, Maberley D. Inflammatory ocular adverse events with the use of oral bisphosphonates: a retrospective cohort study. CMAJ. 2012. Epub April 2.

86. Nancollas GH, Tang R, Phipps RJ, et al. Novel insights into actions of bisphosphonates on bone: differences in interactions with hydroxyapatite. Bone. 2006;38(5):617-627.

87. Sato M, Grasser W, Endo N, et al. Bisphosphonate action. Alendronate localization in rat bone and effects on osteoclast ultrastructure. $J$ Clin Invest. 1991;88(6):2095-2105. 
International Journal of Women's Health

Dovepress

\section{Publish your work in this journal}

The International Journal of Women's Health is an international, peerreviewed open-access journal publishing original research, reports, reviews and commentaries on all aspects of women's healthcare including gynecology, obstetrics, and breast cancer. Subject areas include: Chronic conditions (migraine headaches, arthritis, osteoporosis);
Endocrine and autoimmune syndromes; Sexual and reproductive health; Psychological and psychosocial conditions. The manuscript management system is completely online and includes a very quick and fair peer-review system. Visit http://www.dovepress.com/ testimonials.php to read real quotes from published authors.

Submit your manuscript here: http://www.dovepress.com/international-journal-of-womens-health-journal 